\title{
Atomic Hydrogen Annealing of Gate Dielectric in Pentacene Organic Thin-Film Transistors
}

\author{
Akira HEYA ${ }^{a, *}$, Masahiko SATO ${ }^{a}$, Hiroshi HASEGAWA ${ }^{a}$ and Naoto MATSUO ${ }^{a}$ \\ ${ }^{a}$ Department of Materials Science and Chemistry, University of Hyogo(2167, Shosha, Himeji-shi, Hyogo 671-2280)
}

Keywords : Atomic Hydrogen, Atomic Hydrogen Annealing, Surface Treatment, Organic Thin-Film Transistor, Pentacene

\section{Introduction}

Recently, performance of organic thin-film transistors (OTFTs) has improved. The carrier mobility of pentacene TFT is now comparable to that of amorphous silicon thin-film transistors (TFTs) ${ }^{1)}$. Therefore, it is expected that OTFTs are applicable for use in special applications such as flexible displays and IC tags. The carrier mobility of pentacene TFT depends on the pentacene crystallinity, grain size, and interface properties between the pentacene film and gate insulator because grain boundary scattering, interface roughness scattering, and surface scattering affect the mobility. Therefore, a pentacene film with a large grain and a smooth interface is necessary to improve the carrier mobility.

The grain size and the cystallinity of pentacene film depend on the surface state of the gate insulator. For that reason, the surface energy affects the grain size of the pentacene film and OTFT characteristics. Therefore, various surface treatments using dry and wet processes were investigated to improve the crystallinity of pentacene film and OTFT characteristics ${ }^{2)}$ 4). Plasma treatments using $\mathrm{H}_{2}, \mathrm{O}_{2}$, and $\mathrm{NH}_{3}$ gases are known as methods for improvement of TFT characteristics for dry processing ${ }^{5}$. However, plasma treatments risk damage to electrical devices because of the use of electrical power. Additionally, it is difficult to treat large areas simultaneously.

We have developed a low-temperature surface treatment, named atomic hydrogen annealing (AHA $)^{6}$. Using this method, hydrogen molecules are decomposed by catalytic cracking reactions on a heated catalyzer placed near the substrate. The sample surface is heated using recombination energy from atomic hydrogens to molecules and it is reduced. This method is useful to treat a sample with a large area simply by spreading the catalyzer widely without incurring plasma damage. The decomposition efficiency of $\mathrm{H}_{2}$ is much higher on a heated catalyzer surface than in the gas phase, as in the case of a plasma process ${ }^{7}$.

In this study, the AHA process was applied to improve the electrical characteristics of pentacene OTFT. The effects of AHA on film properties and electrical characteristics of OTFT were investigated.

\section{Experimental}

For this study, Si wafers ((111), n-type, 100-mm diameter, $500 \mu \mathrm{m}$ thick and 0.2-0.4 $\Omega \mathrm{cm})$ were used. Each Si wafer was cleaned using SH solution $\left(\mathrm{H}_{2} \mathrm{SO}_{4}: \mathrm{H}_{2} \mathrm{O}_{2}=1: 3\right)$ at $100{ }^{\circ} \mathrm{C}$ for 600 s. A $350-$ nm-thick $\mathrm{SiO}_{2}$ film was formed by thermal oxidation

\footnotetext{
*E-mail: heya@eng.u-hyogo.ac.jp
}

using a mixture of $\mathrm{O}_{2}$ and $\mathrm{H}_{2} \mathrm{O}$ moisture at $1000{ }^{\circ} \mathrm{C}$ for $1800 \mathrm{~s}$. The AHA apparatus is presented schematically in Fig. 1. A tungsten wire of $0.4 \mathrm{~mm}$ diameter and $400 \mathrm{~mm}$ length was used as a catalyzer. The flow rate of $\mathrm{H}_{2}$ (purity $99.9999 \%$ ) and gas pressure were, respectively, $100 \mathrm{sccm}$ and $30 \mathrm{~Pa}$. The catalyzer temperature $\left(T_{\text {cat }}\right)$ and the treatment time were, respectively, $1500{ }^{\circ} \mathrm{C}$ and $1800 \mathrm{~s}$. The maximum substrate temperature was $110^{\circ} \mathrm{C}$.

The change in surface morphology induced by AHA was investigated using contact-mode atomic force microscopy (AFM). The chemical bond states of the $\mathrm{SiO}_{2}$ surface with and without AHA were examined using X-ray photoelectron spectroscopy (XPS). The XPS profiles were obtained using an Al K $\alpha$ X-ray of $400 \mu \mathrm{m}$ diameter and a neutralization gun. The wide spectra and narrow spectra ( $\mathrm{Si} 2 \mathrm{p}$ and $\mathrm{O} 1 \mathrm{~s})$ were measured respectively at three days and at sixty days after air exposure. The surface properties of samples were evaluated from the contact angle of a water droplet $(1.5 \mu \mathrm{l})$. The pentacene films were deposited by vacuum thermal evaporation five days after AHA treatment. However, the $\mathrm{SiO}_{2} / \mathrm{Si}$ substrate subjected to AHA was kept in a vacuum desiccator until pentacene deposition. The pentacene film deposition was conducted until $1 \mathrm{hr}$ after air exposure. After air exposure, the Au source and drain electrodes were deposited on the pentacene/ $/ \mathrm{SiO}_{2} / \mathrm{Si}$ substrate by electron beam (EB) evaporation, but it was feared that the interface between pentacene and $\mathrm{Au}$ films was degraded by $\mathrm{O}_{2}$ and $\mathrm{H}_{2} \mathrm{O}$ in air. The OTFT pattern was fabricated using a metal-shadow mask.

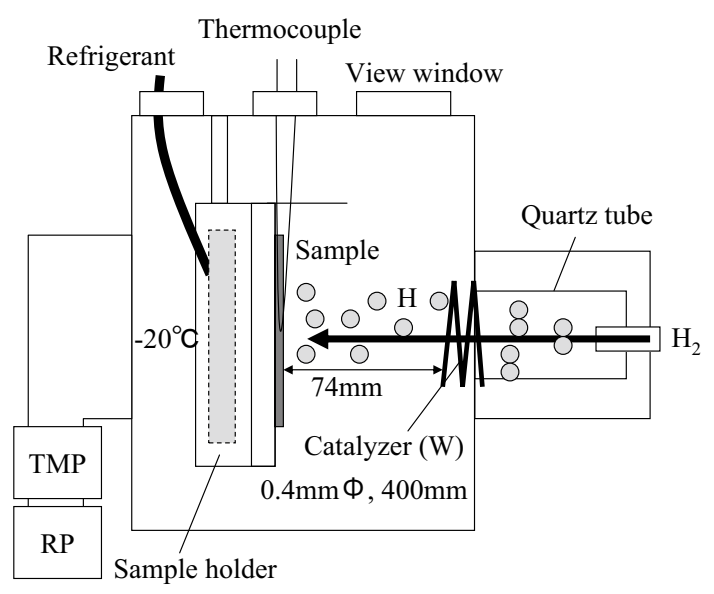

Fig. 1 Schematic diagram of AHA apparatus. The $\mathrm{SiO}_{2} / \mathrm{Si}$ substrate was treated using a chemical reaction and the recombination energy of atomic hydrogen generated by catalytic cracking reactions on a heated catalyzer. 
The sample-holder temperature was RT and base pressure was lower than $2 \times 10^{-4} \mathrm{~Pa}$. The respective thicknesses of pentacene and $\mathrm{Au}$ films were 50 and $300 \mathrm{~nm}$. The channel length and width of OTFT were, respectively, 1 and $10 \mathrm{~mm}$. Electrical characteristics of pentacene OTFT were evaluated at RT in air. The carrier mobility $(\mu)$ was estimated from the linear region of $I_{\mathrm{D}}-V_{\mathrm{D}}$ characteristic by assuming that the carrier transport was band conductivity.

\section{Results and discussion}

The AHA slightly decreased the intensity ratio of $\mathrm{O} 1 \mathrm{~s}$ to $\mathrm{Si} 2 \mathrm{p}(\mathrm{O} /$ Si ratio) in XPS wide spectra. The full width at half maximum (FWHM) of Si2p and O1s were slightly decreased respectively from 1.96 to $1.91 \mathrm{eV}$ and from 1.76 to $1.72 \mathrm{eV}$ by AHA. The FWHM of the XPS peak for $\mathrm{SiO}_{2}$ surface relates to crystallinity. Results show that the $\mathrm{SiO}_{2}$ adopted a stable structure by removal of a weak bond in $\mathrm{SiO}_{2}$ network by atomic hydrogen. In addition, the peak positions of $\mathrm{Si} 2 \mathrm{p}$ and $\mathrm{O} 1 \mathrm{~s}$ were changed, respectively from $104.1 \mathrm{eV}$ to $103.6 \mathrm{eV}$ and from $532.7 \mathrm{eV}$ to $533.0 \mathrm{eV}$ by AHA. Reportedly, the peak attributable to $\mathrm{O}-\mathrm{Si}$ at $530.9 \mathrm{eV}$ is a trap site of the carrier ${ }^{8)}$. Apparently, the peak at $530.9 \mathrm{eV}$ was decreased by AHA.

The surface properties of $\mathrm{SiO}_{2}$ with and without AHA are presented in Table 1. The refractive index was decreased slightly from 1.46 to 1.45 . The contact angle of a water droplet on the $\mathrm{SiO}_{2} / \mathrm{Si}$ substrate was increased from $64^{\circ}$ to $73^{\circ}$ by AHA, which implies that the decrease in refractive index was related to reduction of the

Table 1 Surface properties of $\mathrm{SiO}_{2}$ with and without AHA.

\begin{tabular}{lcc}
\hline & Without & With AHA \\
\hline Ra roughness $(\mathrm{nm})$ & 0.15 & 0.13 \\
Film thickness $(\mathrm{nm})$ & 360 & 363 \\
Refractive index & 1.46 & 1.45 \\
XPS intensity ratio of O1s/Si2p & 5.58 & 5.41 \\
FWHM of Si2p peak $\left(^{\circ}\right)$ & 1.96 & 1.91 \\
Contact angle of droplet $\left(^{\circ}\right)$ & 64 & 73 \\
$E_{\mathrm{s}}($ dyne $/ \mathrm{cm})$ & 42 & 39 \\
\hline
\end{tabular}

Surface energy $\left(E_{\mathrm{s}}\right)$ was estimated from the contact angle.

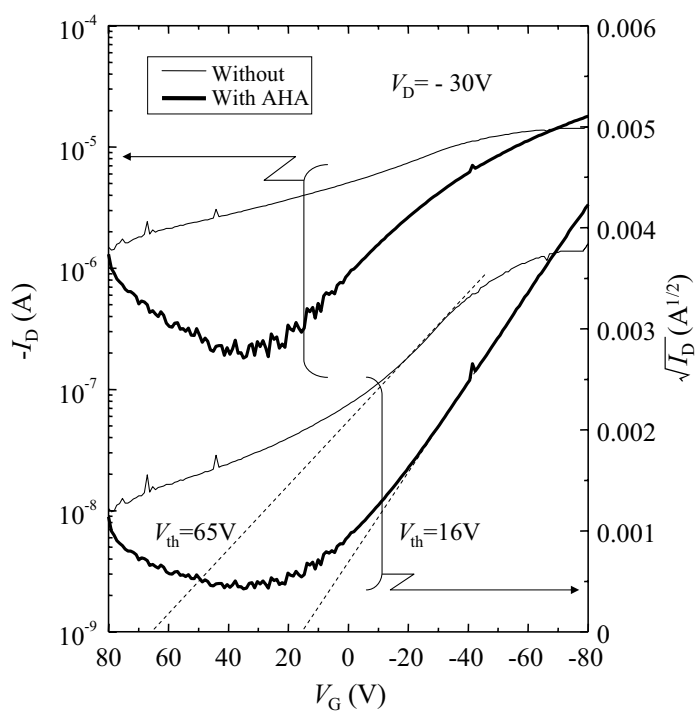

Fig. $2 I_{\mathrm{D}}-V_{\mathrm{G}}$ and $\sqrt{I_{\mathrm{D}}}-V_{\mathrm{G}}$ characteristics of the pentacene OTFTs with and without AHA. The value of $V_{\mathrm{D}}$ was $-30 \mathrm{~V}$. The $V_{\mathrm{th}}$ was estimated from $\sqrt{I_{\mathrm{D}}}-V_{\mathrm{G}}$ characteristics.
$\mathrm{SiO}_{2}$ surface. The AFM image shows that the surface roughness ( $\mathrm{Ra})$ of $\mathrm{SiO}_{2} / \mathrm{Si}$ substrates with and without AHA was not changed by AHA. The decrease in grain size by surface roughness ${ }^{9)}$ and degradation of OTFT characteristics by interface scattering are negligible. Results show that the surface state of $\mathrm{SiO}_{2}$ can be modified by AHA without an increase in surface roughness.

The dendritic grain was observed in AFM images of pentacene films. The respective grain sizes of pentacene with and without AHA were 0.46 and $0.41 \mu \mathrm{m}$. The grain size was increased slightly because the surface energy was decreased by AHA.

Fig. 2 shows $I_{\mathrm{D}}-V_{\mathrm{G}}$ and $\sqrt{I_{\mathrm{D}}}-V_{\mathrm{G}}$ characteristics of the pentacene OTFTs. The respective mobility values of OTFT with and without AHA were 0.042 and $0.051 \mathrm{~cm}^{2} / \mathrm{Vs}$. The value of $V_{\text {th }}$ decreased from 65 to $16 \mathrm{~V}$ and that of $I_{\text {on/off }}$ improved from 10 to 100 by AHA. Reportedly, silanols $(\mathrm{Si}-\mathrm{OH})$ exist on the $\mathrm{SiO}_{2}$ surface and have negative charge ${ }^{10)}$. In addition, a dangling bond exists at the interface between the $\mathrm{SiO}_{2}$ film and $\mathrm{Si}$ substrate, which indicates that negative charges exist on the $\mathrm{SiO}_{2}$ film and at the interface of the $\mathrm{SiO}_{2}$ and $\mathrm{Si}$ substrate. In this case, the channel was formed without application of the gate voltage. Consequently, the $V_{\text {th }}$ and off current was high and the $I_{\text {on/off }}$ were very low for OTFT fabricated without AHA. Contact angle measurements show that the $\mathrm{SiO}_{2}$ surface hydrophobicity was increased by AHA. This result implies that the hydroxyl group on the surface is removable using atomic hydrogen. Additionally, atomic hydrogen passivates and depassivates $\mathrm{Si}$ dangling bonds at the $\mathrm{Si}(111) / \mathrm{SiO}_{2}$ interface via the reactions $\mathrm{P}_{\mathrm{b}}+\mathrm{H}^{0} \rightarrow \mathrm{P}_{\mathrm{b}} \mathrm{H}$ and $\mathrm{P}_{\mathrm{b}} \mathrm{H}+\mathrm{H}^{0} \rightarrow \mathrm{P}_{\mathrm{b}}+\mathrm{H}_{2}{ }^{11)}$. It is considered that AHA has an effect of removal of negative charges on $\mathrm{SiO}_{2}$ film and at the interface between $\mathrm{SiO}_{2}$ and the $\mathrm{Si}$ substrate.

\section{Conclusions}

The pentacene film grain size was not increased drastically by AHA, although the surface energy of $\mathrm{SiO}_{2}$ film was changed from 42 to 39 dyne/cm by AHA. However, $V_{\text {th }}$ was decreased from 65 to $16 \mathrm{~V}$ and the on/off ratio was improved from 10 to 100 by AHA. The effect of AHA is related to the removal of negative charges on $\mathrm{SiO}_{2}$ films and the interface of $\mathrm{SiO}_{2} / \mathrm{Si}$ substrate by atomic hydrogen. Results obtained in this study demonstrate that AHA is a promising technique for improving OTFT characteristics.

(Received April 19, 2010 ; Accepted May 10, 2010)

\section{References}

1) I. Kymissis, C. D. Dimitrakopoulos and S. Purushothaman ; IEEE Trans. Electron Devices, 48, 1060 (2001).

2)F. D. Angelis, S. Cipolloni, L. Mariucci and G. Fortunato ; Appl. Phys. Lett., 86, 203505 (2005).

3) A. S. Killampalli and J. R. Engstrom ; Appl. Phys. Lett., 88, 143125 (2006).

4) M. W. Lee and C. K. Song ; Jpn. J. Appl. Phys., 42, 4218 (2003).

5) J.W.H. Smith and I.G. Hill: J. Appl. Phys., 101, 044503 (2007).

6) A. Heya and N. Matsuo ; Jpn. J. Appl. Phys., 46, 3545 (2007).

7) H. Umemoto, K. Ohara, D. Morita, Y. Nozaki, A. Masuda and H. Matsumura ; J. Appl. Phys., 91, 1650 (2002).

8) S. Kang, J. Park, S. Jung, H. Lee, P. Son, J. C. Kim, T. Yoon and M. Yi ; Jpn. Appl. Phys., 46, 2696 (2007).

9) K. Itaka, N. Myojin, M. Yamashiro, J. Yamaguchi and H. Koinuma ; Jpn. J. Appl. Phys., 44, 6249 (2005).

10) L.-L.Chua, J. Zaumseil, J. Chang, E. Ou, P. Ho, H. Sirringhaus and R. Friend ; Nature, 434, 194 (2005).

11) E. Cartier, J. H. Stathis and D. A. Buchanan ; Appl. Phys. Lett., 63, 1510 (1993). 